\title{
Structural property distribution of the cervical endplate and the correlation with CT measured subchondral bone density
}

Nathaniel R. Ordway $\cdot$ Yen-Mou Lu $\cdot$ Xingkai Zhang • Chin-Chang Cheng $\cdot$ Huang Fang $\cdot$ Amir H. Fayyazi

Published online: 2 October 2007

(C) Springer-Verlag 2007

\section{Erratum to: Eur Spine J}

\section{DOI 10.1007/s00586-007-0482-z}

Owing to an unfortunate oversight, the incorrect title "Correlation of cerival endplate strength with CT measured subchondral bone density" appeared in the original article.

The online version of the original article can be found under doi:10.1007/s00586-007-0482-z.

N. R. Ordway · A. H. Fayyazi $(\bowtie)$

Department of Orthopedics, SUNY Upstate Medical Center,

550 Harrison Street, Syracuse, NY 13202, USA

e-mail: amirfayyazi@yahoo.com

Y.-M. Lu

Department of Orthopedic Surgery, Kaohsiung Medical

University, Kaohsiung, Taiwan

C.-C. Cheng

Chang Gung Memorial Hospital, ChiaYi, Taiwan

X. Zhang

Institute of Orthopedics and Traumatology, Shanghai Jiaotong

University Medical College Ruijin Hospital, Shanghai, China

H. Fang

Tongji Medical College, Huazhong University of Science

and Technology, Wuhan, China 